African Journal of Microbiology Research Vol. 5(23), pp. 3930-3935, 23 October, 2011

Available online http://www.academicjournals.org/AJMR

ISSN 1996-0808 @2011 Academic Journals

Full Length Research Paper

\title{
Detection of Enterococcus species in groundwater from some rural communities in the Mmabatho area, South Africa: A risk analysis
}

\author{
Collins Njie Ateba* and Merapelo Duke Maribeng
}

Department of Biological Sciences, School of Environmental and Health Sciences, Faculty of Agriculture,
Science and Technology, North-West University - Mafikeng Campus, Private Bag X2046, South Africa.

Accepted 9 September, 2011

\begin{abstract}
In South Africa, individuals who reside in most rural areas do not have access to portable water and they rely on untreated water from boreholes. This exposes them to disease causing microorganisms. The aim of the study was to isolate and determine the antibiotic susceptibility profiles of enterococcus in ground water from three rural communities in the Mmabatho area, North-West Province of South Africa. Enterococcus selective agar (ESA) was used for selective isolation of Enterococci species. The identities of the isolates were determined using preliminary (Gram staining, catalase test, oxidase test) and confirmatory (API 20 Strep and the Prolex ${ }^{\mathrm{TM}}$ Streptococcal Grouping Rapid Latex Agglutination test kit) test. Two hundred and twenty five presumptive isolates were screened and 139 were positively identified. Three enterococcus species were identified; Enterococcus faecium $(71.2 \%)$, Enterococcus faecalis (23.0\%) and Enterococcus avium (5.8\%). A large proportion of the isolates (73.4\%) belonged to the Lands field group D serotype when compared to the G group (26.6\%). A large proportion of the isolates (75 to 100\%) from Ramosadi and Seweding were resistant to vancomycin, penicillin G, erythromycin, chloramphenicol, oxytetracycline, amoxycilin and sulphamethoxazole. Isolates from Mothlabeng showed little resistance against these drugs. The identification of vancomycin-resistant enterococci was a cause for concern since they pose a severe challenge to the medical profession. The natural hosts of $E$. faecium and $E$. faecalis are humans and animals. From these results, it is proposed that the isolates could have originated from contamination of these water sources with faeces since most of the boreholes are constructed near the pit toilets.
\end{abstract}

Key words: Enterococcus faecium, Enterococcus faecalis, Enterococcus avium, Vancomycin resistant enterococci (VRE), multiple antibiotic resistance.

\section{INTRODUCTION}

Water is a very important resource for life (WHO, 2003). Access to safe drinking water is a fundamental human need and therefore a basic right of every individual, since

*Corresponding author. E-mail: atebacollins1@hotmail.com.

Abbreviations: ESA, Enterococcus selective agar; API, analytical profile index; VRE, vancomycin resistant enterococci; MAR, multiple antibiotic resistant. contaminated water jeopardizes both the physical and social health to consumers (WHO, 2003). In many countries, including South Africa, the shortages of water, human activities and industrialization have been found to significantly affect the quality of water (Martellini et al., 2005). South Africa is a semi arid area that has a very low rainfall (Chamaille-Jammes et al., 2007). While the government can be commended on efforts to improve the quality of water that is supplied to residential quarters, in rural areas, most individuals do not have access to portable water and therefore rely on water from 
alternative sources such as rivers, dams and boreholes for survival and for use in household activities (Chamaille-Jammes et al., 2007). These water sources are usually unprotected and are therefore subject to contamination with microbes of faecal origin such as Escherichia coli, Enterococcus species and Salmonella species (Reeves and Grant, 2004).

The consumption of contaminated water has severe health implications on humans by causing diseases that include diarrohoea, endocarditis, and bacterimia (Nannini et al., 2005; Takeuchi et al., 2005). These diseases pose a challenge to the medical profession even in countries that have more advanced health care facilities if caused by multiple antibiotic resistant strains (Birgul and Altan, 2005; Takeuchi et al., 2005). It is therefore beneficial for portable water to be free of microbial contamination in order to reduce the possibility of transmitting disease causing microbes to consumers (WHO, 2003).

Enterococci are facultative anaerobic, Gram positive cocci that live as normal flora in the gastrointestinal tract of humans and animals (Gambaratto et al., 2000, Kiem et al., 2003). Enterococcus species are indicators which when found in water and food products indicate contamination from faeces from both animals and humans (Franz et al., 2001, He and Jiang, 2005; Valenzuela et al., 2008). Contamination is usually associated with poor hygiene practices and this explains the need to implement proper hygiene standards when handling food products (Foulquie-Moreno et al., 2006). Although, more than twenty species have been classified, Enterococcus faecium and Enterococcus faecalis are the most frequently indentified in humans, animals, food products and water (Eaton and Gasson, 2001; Radu et al., 2001; Facklam, 2002; Giraffa, 2002). Enterococci are opportunistic pathogens and most often would cause disease on their hosts if the immune system is suppressed (Fisher and Philips, 2009). In a country like South Africa where the incidence of HIV/AIDS is high, the impact of these pathogens cannot be overemphasized. Moreover, the ability of Enterococcal cells to resist destruction by a wide range of antibiotics gives the organisms the potential to survive in hospital environments and disseminate resistant strains if proper hygiene is not implemented (Leclercq et al., 1998).

Despite the problems that residents in most rural communities in the North-West Province of South Africa face as a result of consuming untreated water, only one study has been documented (Moneoang and Bezuidenhout, 2009). Moreover, the aforementioned study evaluates the prevalence of Enterococcus species in pigs. The present study was aimed at providing information on the occurrence of Enterococcus species from water obtained from boreholes in some rural communities in the Mmabatho area in the North-West Province of South Africa but with emphasis on the antibiotic resistance profiles of the isolates.

\section{MATERIALS AND METHODS}

\section{Area of the study}

The research was conducted at the North-West University-Mafikeng Campus, South Africa. Fifteen ground water samples were collected from three villages in Mmabatho. This included 5 from Motlhabeng, 5 from Ramosadi and 5 from Seweding.

\section{Sample collection}

Samples were collected from borehole taps. Prior to collecting the samples, the taps were made to run for about $1 \mathrm{~min}$. Water samples were collected into sterile $500 \mathrm{ml}$ Duran Schott bottles and were immediately transported on ice to the laboratory for analysis.

\section{Sample analysis \\ Selective isolation of Enterococci species}

Water samples were analysed within two hours upon arrival in the laboratory according to standard methods (APHA, 1998). An aliquot of $100 \mathrm{ml}$ from each sample was filtered using $0.45 \mu \mathrm{m}$ filter paper

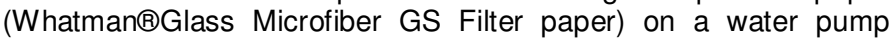
(model Sartorius 16824). A sterile forcep was used to remove the membrane filters from the machine. These filter papers were placed on ESA, (Biolab, South Africa). The plates were incubated aerobically at $45^{\circ} \mathrm{C}$ for $24 \mathrm{~h}$ and typical black colonies were considered as potential Enterococci species. These isolates were sub-cultured on ESA plates and incubated aerobically at $45^{\circ} \mathrm{C}$ for $24 \mathrm{~h}$.

\section{Control strains}

E. faecalis (ATCC 29212) and E. faecium (ATCC 6569) were used as positive control strains.

\section{Bacterial identification}

Presumptive isolates were identified using the following criteria:

\section{Cellular morphology}

Isolates were Gram stained using standard methods (Cruikshank et al., 1975). Gram-positive cocci were subjected to both preliminary and confirmatory identification tests for Enterococcus species.

\section{Preliminary biochemical identification tests for Enterococci}

Oxidase test: The oxidase test was performed using test reagent from Pro-Lab Diagnostics-United Kingdom and the test was performed as instructed by the manufacturer (Whatman International Ltd, Maidstone, England). Enterococci are oxidase negative hence all isolates that satisfied this preliminary identification criteria were retained.

Catalase test: The catalase test is designed to detect the presence of the catalase enzyme in most aerobic and facultative anaerobic bacteria that contain the cytochrome system. Enterococci and 
Table 1. Details of antibiotics that were used in the study.

\begin{tabular}{lccccc}
\hline Group & Ab & Disc conconcentration $(\mu \mathbf{g})$ & $\mathbf{R}$ & $\mathbf{I}$ & $\mathbf{S}$ \\
\hline Aminoglycosides & SMX & $300^{\mathrm{a}}$ & $\leq 11$ & $12-14$ & $\geq 15$ \\
& & & & & \\
& AP & $10^{\mathrm{a}}$ & $\leq 11$ & $12-14$ & $\geq 15$ \\
Beta -Lactams & PG & $10^{\mathrm{a}}$ & $\leq 20$ & $21-28$ & $\geq 29$ \\
& GM & $10^{\mathrm{a}}$ & $\leq 12$ & - & $\geq 13$ \\
Glycopeptides & A & $10^{\mathrm{a}}$ & $\leq 13$ & $14-16$ & $\geq 17$ \\
Tetracyclines & VA & $30^{\mathrm{c}}$ & $\leq 9$ & $10-11$ & $\geq 12$ \\
Phenols & OT & $30^{\mathrm{c}}$ & $\leq 14$ & $15-18$ & $\geq 19$ \\
Marcrolides & C & $30^{\mathrm{c}}$ & $\leq 12$ & $13-17$ & $\geq 18$ \\
\hline
\end{tabular}

The superscripts ${ }^{a}$ to ${ }^{d}$ indicate the generally accepted concentrations of the discs according to the standard method stipulated by the manufacturer, Mast Diagnostics, Merseyside, United Kingdom.

Streptoccoci are exceptions and do not possess the enzyme. Catalase enzymes decompose hydrogen peroxide to water and oxygen. The catalase test was performed by reacting a drop of $2 \%$ hydrogen peroxide and viable presumptive enterococci on a clean microscope slide. Enterococcus species are catalase negative hence all isolates that satisfied this preliminary identification criterion were subjected to further confirmatory tests.

\section{Confirmatory identification tests for Enterococci}

\section{Analytical profile index API 20 strep}

The identities of all presumptive Enterococcus spp. that satisfied the preliminary identification characteristics were confirmed using the analytical profile index (API) 20 Strep test. The test was performed as instructed by the manufacturer (BioMerieux®, France). The indices obtained after reading the results were interpreted using the API web software (BioMerieux® S.A.).

\section{Serotyping}

A Prolex ${ }^{\mathrm{TM}}$ Streptococcal Grouping Latex test kit obtained from PRO-LAB Diagnostics - U.K was used for serological seperation of Enterococcus spp. into Lancefield groups $D$ and $G$. The test was performed by reacting a cell wall specific carbohydrate extract of isolates with nitrous acid reagents (positive $D$ and $G$ antisera). Positive reactions were recorded when extracts agglutinated with specific reagents. However, the A antiserum that was provided in the kit was used as a negative enterococci control for both the control strains and the test isolates.

\section{Antibiotic susceptibility test}

Antibiotic susceptibility tests were performed on all Enterococci species to determine their antibiotic resistant profiles using the Kirby-Bauer disc diffusion technique (Kirby et al., 1966). Before antibiotic sensitivity testing, the isolates were revived by subculturing onto ESA plates. The plates were incubated aerobically at $37^{\circ} \mathrm{C}$ for $24 \mathrm{~h}$. Bacterial suspensions were prepared using pure isolates and aliquots of $100 \mu \mathrm{l}$ from these suspensions were spreadplated on Mueller Hinton agar (Biolab, Merck, South Africa). The susceptibilities of the isolates against a panel of ten different antibiotic discs obtained from Mast Diagnostics - United Kingdom were determined. The antibiotic discs were gently pressed onto inoculated Mueller Hinton agar to ensure intimate contact with the surface and plates were incubated aerobically at $37^{\circ} \mathrm{C}$ for $24 \mathrm{~h}$ (NCCLS, 1999). The antibiotic inhibition zone diameters were measured and results obtained were used to classify isolates as being resistant, intermediate resistant or susceptible to a particular antibiotic based on standard reference values (NCCLS, 1999). Table 1 indicates the details of antibiotics that were used in the study. The antibiotics tested were those to which resistance have been reported in the area (Ateba and Bezuidenhout, 2008; Moneoang and Bezeidenhout, 2009). Moreover, some antibiotics that are used to treat human infections were also included.

\section{Statistical analysis}

Statistical analysis was done using SPSS software (version 14.0). Pearson's correlation product of moment $(P<0.05)$ was used to determine whether the antibiotics tested exhibited similar reactions against the Enterococci spp. isolated from the different sampling stations.

\section{RESULTS}

\section{Occurrence of Enterococcus spp. in ground water samples}

The number of isolates that satisfied both the preliminary and confirmatory identification tests is shown in Table 2. A total of 228 presumptive isolates were screened and 139 were positively identified as enterococci. The proportion enterococci isolated was higher in water obtained from Motlabeng (54.7\%) than in Ramosadi $(23.0 \%)$ and Seweding (22.3\%). Although, three different enterococci species were isolated in the study, $E$. faecium $(71.2 \%)$ was the most predominant in all the sampled sites. However E. faecalis and E. avium were isolated at 23.0 and $5.7 \%$, respectively. E. avium was not isolated from Ramosadi and Seweding. A large proportion $(78.4 \%)$ of the isolates agglutinated with the $D$ 
Table 2. The percentages of Enterococci spp. isolated from the different sampling sites.

\begin{tabular}{|c|c|c|c|c|c|c|c|c|}
\hline \multirow{2}{*}{ Village } & \multirow{2}{*}{$\begin{array}{l}\text { Gram staining } \\
\text { (+ve coccus) }\end{array}$} & \multirow{2}{*}{$\begin{array}{l}\text { Oxidase } \\
\text { test (-ve) }\end{array}$} & \multirow{2}{*}{$\begin{array}{l}\text { Catalase } \\
\text { Test (-ve) }\end{array}$} & \multicolumn{3}{|c|}{$\begin{array}{l}\text { API } 20 \text { Strep (No. of the different } \\
\text { species positively identified) }\end{array}$} & \multicolumn{2}{|c|}{$\begin{array}{l}\text { Serotyping (No. +ve for } \\
\text { different serogroups) }\end{array}$} \\
\hline & & & & E. faecium & E. faecalis & E. avium & D & G \\
\hline $\mathrm{MO}(\mathrm{N}=76)^{*}$ & 76 & 76 & 76 & 45 & 23 & 8 & 54 & 22 \\
\hline $\mathrm{RA}(\mathrm{N}=32)^{*}$ & 76 & 76 & 76 & 23 & 9 & 0 & 32 & 0 \\
\hline $\mathrm{SE}(\mathrm{N}=32)^{*}$ & 76 & 76 & 76 & 31 & 0 & 0 & 16 & 15 \\
\hline Total & 228 & 228 & 228 & 99 & 32 & 8 & 102 & 37 \\
\hline$\%$ & & & & 71.2 & 23.0 & 5.8 & & \\
\hline
\end{tabular}

Table 3. The percentages of Enterococcus spp. isolated from the different sampling sites.

\begin{tabular}{lccccccccc}
\hline Sample source & AP & GM & OT & VA & C & E & PG & A & SMX \\
\hline MO & 7 & 16 & 21 & 19 & 20 & 32 & 12 & 28 & 76 \\
NT=76 NR\% & 9.2 & 21 & 27.6 & 25 & 26.3 & 42.1 & 15.7 & 36.8 & 100 \\
& & & & & & & & & \\
RA & 6 & 13 & 30 & 24 & 29 & 30 & 25 & 32 & 32 \\
NT=32 NR\% & 18.7 & 40.6 & 93.7 & 75 & 90.6 & 93.7 & 78.1 & 100 & 100 \\
SE & 2 & 1 & 18 & 12 & 22 & 31 & 5 & 31 & 31 \\
NT=31 NR\% & 6.4 & 3.2 & 58 & 38.7 & 70.9 & 100 & 16.1 & 100 & 100 \\
\hline
\end{tabular}

${ }^{*}=$ No. tested; $\mathrm{MO}=$ motlhabeng, $\mathrm{RA}=$ ramosadi, $\mathrm{SE}=$ seeding.

antiserum when compared to the $\mathrm{G}(21.6 \%)$. The natural hosts of $E$. faecium and $E$. faecalis are humans and animals. From these results, it is proposed that the isolates could have originated from contamination of these water sources with faeces since most of the boreholes were constructed near the pit toilets.

\section{Percentage antibiotic resistance of Enterococci species}

All the 139 enterococci isolated were tested to determine their antibiotic susceptibility profiles against a panel of 9 different antimicrobial agents. Results obtained are depicted in Table 3. A large proportion (75 to 100\%) of the isolates from Ramosadi village were resistant to sulphamethothazole, amoxycillin, erythromycin, chloramphenicol, vancomycin, tetracycline and penicillin. Although a similar trend was seen for isolates from Seweding, the proportion of isolates that were resistant to tetracycline and vancomycin were much lower (58 and $38.7 \%$, respectively). However, isolates from Motlhabeng showed little resistance against these drugs except for sulphamethoxazole in which all isolates were resistant. A relatively smaller proportion of the isolates (6.4 to 18.7\%) tested were resistant to ampicillin. Moreover, only very few of the isolates (15.7 to $16.1 \%$ ) from Motlhabeng and Seweding were resistant to penicillin G. A cause for concern was the identification of vancomycin resistant enterococci (VRE) in samples obtained from all the three sampling sites despite the fact that the drug is not used in the area. These isolates may pose a severe challenge to both the medical and veterinary professions in the area. It is thus recommended that water samples from these sources be treated before consumption.

\section{DISCUSSION}

In Motlabeng village the boreholes are constructed very close to the pit toilets than in the other two sampling areas. Moreover, Motlabeng is more populated than Seweding and Ramosadi since it is closer to the North West University. Home owners in this village construct hostels in their compounds and these are rented by university students since these accommodation facilities are cheaper than those on campus or in the unit residential areas. However, there is a public health problem associated with this practice. In Seweding and Ramosadi houses are sparely located and most residents have their boreholes constructed in such a way that the water passes through a bed of stones and undergoes 
some form of treatment. Water from these sources is also stored in elevated closed tanks that are connected to taps. This minimizes contamination and can account for the results obtained in these sampling sites.

A large proportion (78.4\%) of the isolates agglutinated with the $D$ antisera when compared to the $G(21.6 \%)$. All the test isolates and the enterococci control strains were negative when reacted with the $A$ antiserum. This observation is in agreement with the report that Lancefield's groups $D$ and $G$ are specific for the genus Enterococcus while groups $\mathrm{A}, \mathrm{B}, \mathrm{C}, \mathrm{E}$ and $\mathrm{F}$ belong to the genus Streptococcus (Facklam, 2002; Kohler, 2007).

Three enterococcus species viz E. faecium, E. avium and $E$. faecalis were indentified in the study. It has been reported that $E$. faecalis is more prevalent in the gastrointestinal tract of humans than E. faecium (Noble, 1978). In the present study, E. faecium than E. faecalis was isolated. Therefore, and in disagreement to a previous study (Noble, 1978) with respect to the distribution of the species, enterococci were predominant in Motlabeng than in Ramosadi and Seweding. It is suggested that the observed trend could have resulted from the fact that Motlabeng is more populated hence the level of contamination of ground water with faeces from humans is high.

A further objective was to determine the antibiotic resistance profiles of enterococci isolated. A large proportion of Enterococcus species were resistant to three or more antibiotics and hence were termed multiple antibiotic resistant (MAR) isolates. Moreover, isolates were most often resistant to sulphamethoxazole, erythromycin, chloramphenicol, amoxycillin and tetracycline. This is in agreement with a previous report (Moneoang and Bezuidenhout, 2009). Tetracycline is easily accessible over the counter and hence the most commonly used antibiotics on animals in the area. However, only a small proportion (6.2-18.7\%) of the isolates from the three sampling sites were resistant to ampicillin and gentamycin. Ampicillin is also commonly used in the area hence the results presented do not correspond with the usage of the drug in the area. A large proportion $(75 \%)$ of the isolates from Ramosadi and a reasonable proportion ( 25 to $38.7 \%$ ) of the isolates from Motlabeng and Seweding, respectively were resistant to vancomycin. Although a similar observation has been reported, the VRE isolates were obtained from pigs (Hasmann et al., 2005). Vancomycin is not used in both veterinary and human medicine in the area. Thus the identification of Vancomycin resistant enterococci (VRE) was a cause for concern. VRE may pose a severe challenge to humans since it is very difficult to treat infections they cause. Constant monitoring of the antibiotic resistant profiles of enteroccoci in ground and recreational water sources could provide a comprehensive data of the resistant patterns of these pathogens in the area. This would improve information on treatment options for enterococcal infections in humans.

\section{Conclusion}

The present study examined the level of contamination of ground water with Enterococcus species and the species distribution. Results indicated the presence of these faecal indicators in water that is consumed by individuals in these rural communities in the North West Province. This may have resulted from the fact that individuals who live in these villages do not practice proper hygiene and have limited access to sanitary facilities hence increasing the chances of contaminating the water with faecal matter. The provision of proper water management systems and treated safe water supply to residents in these communities cannot be overemphasized. The detection of large numbers of MAR isolates in water was of concern as this could lead to the dissemination of antimicrobial resistant strains that have negative clinical implications. The results presented herein demonstrate the need for a continued surveillance of antimicrobial resistance among these water and food-borne pathogens so as to improve public health standards.

\section{ACKNOWLEDGEMENTS}

Authors are grateful to the North-West University, Mafikeng Campus for providing the funds and work space needed to conduct the research. The assistance received from the laboratory technician Mrs. Rika Hyser is highly acknowledged.

\section{REFERENCES}

APHA (1998). Standard methods for the examination of Water and Wastewater, $19^{\text {th }}$ ed. American Public Health Association, Washington DC.

Ateba CN, Bezuidenhout CC (2008). Characterization of Escherichia coli 0157 strains from humans, cattle and pigs in the North-West Province, South Africa. Inter. J. Food Microbiol., 128: 181-188.

Birgul K, Altan A (2005). Antimicrobial resistance of enterococci in Turkey. Inter. J. Antimicrob. Agents, 25: 535-538.

Chamaillé-Jammes S, Valeix M, Fritz H (2007). Managing heterogeneity in elephant distribution: Interactions between elephant population density and surface-water availability. J. Appl. Ecol., 44: 625-633.

Cruikshank R, Duguid JP, Marmoin BP, Swain RH (1975). Medical Microbiology, $12^{\text {th }}$ Ed, New York.Longman Group Limited 2, p. 34.

Eaton TJ, Gasson MJ (2001). Molecular screening of Enterococcus virulence determinants and potential for genetic exchange between food and medical isolates. Appl. Environ. Microbiol., 67: 1628 -1635.

Facklam R (2002). What happened to streptococci: Overview of taxonomic and nomenclature changes. Clin. Microbiol. Rev., 15: 613630.

Fisher K, Phillips C (2009). The ecology, epidemiology and virulence of Enterococcus. Microbiology, 155: 1749-1757.

Foulquie-Moreno MR, Sarantinopoulos P, Tsakalidou E, DeVuyst L (2006). The role and application of enterococci in food and health. Int. J. Food Microbiol., 106: 1-24.

Franz CMAP, Muscholl-Silberhorn AB, Yousif NMK, Vancanneyt M (2001). Antibiotic resistance among enterococci isolated from 
food. Appl. Environ. Microbiol., 67: 4385-4389.

Gambaratto K, Ploy M, Turlure P, Grelaud C, Martin C, Bordessoule D,

Denies F (2000). Prevalence of vancomycin resistant enterococci in faecal samples from hospitalized patients and non-hospitalised patients of France. J. Clin. Microbiol., 38: 620-624.

Giraffa G (2002). Enterococci from foods. FEMS Microbiol. Rev., 26: 163-171.

Hasmann H, Villadsen AG, Aarestrup FM (2005). Diversity and stability of plasmids from glycopeptides resistant (GRE) Enterococcus faecium isolated from pigs in Denmark. Microb. Drug Resist., 11: 178-184.

He JW, Jiang S (2005). Quantification of enterococcci and human adenoviruses in environmental samples by real-time PCR. Appl. Microbiol., 71: 2250-2255.

Kiem M, Wichmann-Schauer H, Peters J. Lüppo E (2003). Species identification and detection of vancomycin resistance genes in enterococci of animal origin by multiplex PCR. Inter. J. Food Microbiol., 88: 305-309.

Kohler W (2007). The present state of species within the genera Streptococcus and Enterococcus. Int. J. Food Microbiol. 297: 133150.

Kirby WMM, Bauer AW, Sherris JC, Turck M (1966). Antibiotic susceptibility testing by single disc method. Am. J. Clin. Pathol., 45: 4

Leclercq R, Derlot E, Duval J, Courvalin P (1988). Plasmid-mediated resistance to vancomycin and teicoplanin in Enterococcus faecium. N. Engl. J. Med., 319: 157-161.

Martellini A, Payment P, Villemur R (2005). Use of eukaryotic mitochondrial DNA to differentiate human, bovine, porcine and ovine sources in focally contaminated surface water. Water Res., 39(4): 541-548.
Moneoang MS, Bezeidenhout CC (2009). Characterization of enterococci and Escherichia coli isolated from commercial and communal pigs from Mafikeng in the North-West Province, South Africa. Afr. J. Microbiol. Res., 3(3): 88-96.

Nannini EC, Teng F, Sigh KV, Murray BE (2005). Decreased virulence of a gls24 mutant of Enterococcus faecalis OG1RF in an experimental endocarditis model. Infect. Immun., 73: 7772-7774.

National Committee for Clinical Laboratory Standards (1999). Performance standards for antimicrobial disc and dilution susceptibility test for bacteria isolated from animals. National Committee for Clinical Laboratory Standards, Wayne, Pennsylvania, Approved Standards M 31-A19, p. 11.

Noble CJ (1978). Carriage of group D streptococci in the human bowel. J. Clin Pathol., 31: 1182-1186.

Radu S, Toosa H, Rahim RA, Reezal A, Ahmad M, Hamid AN, Rusul G, Nishibuchi M (2001). Occurrence of the vanA and vanC2/C3 genes in Enterococcus species isolated from poultrty sources in Malaysia. Diag. Microbiol. Infect. Dis., 39: 145-153.

Reeves RL, Grant SB (2004). Scaling and management of faecal indicator bacteria in runoff from a coastal urban watershed in southern California. Environ. Sci. Technol., 38(9): 2637-2648.

Takeuchi K, Tomita H, Fujimoto S, Kudo M, Kuano H, Ike Y (2005). Drug resistance of Enterococcus faecium clinical isolates and the conjugative transfer of gentamycin and erythromycin resistance traits. FEMS Microbiol. Lett., 243: 347-354.

Valenzuela AS, Omar NB, Abriouel H, López RL, Ortega E, Cañamero MM, Gálves A (2008). Risk factors in enterococci isolated from foods in Morocco: Determination of antimicrobial resistance and incidence of virulence traits. Food Chem. Toxicol., 46: 2648-2652.

World Health Organization (2003). Emerging Issues in Water and Infectious Disease, World Health Organization, Geneva, Switzerland. 